\title{
Daclatasvir combined with peginterferon- $\alpha$ and ribavirin for the treatment of chronic hepatitis C: a meta-analysis
}

\author{
Qin Peng ${ }^{1 \dagger}$, Kang $\mathrm{Li}^{2 \dagger}$, Ming Rong $\mathrm{CaO}^{3 \dagger}$, Cai Qun Bie${ }^{4}$, Hui Jun Tang ${ }^{4}$ and Shao Hui Tang ${ }^{1 *}$
}

\begin{abstract}
Daclatasvir, a HCV NS5A inhibitor, is a new direct-acting antiviral drug for chronic hepatitis C (CHC). This study aimed to evaluate the efficacy and safety of daclatasvir combined with peginterferon-a (pegIFN- $a$ ) and ribavirin (RBV) for the treatment of CHC. The databases of PUBMED, EMBASE, COCHRANE, WANFANG, and CNKI were retrieved to identify eligible studies. Pooled risk ratio (RR) and $95 \%$ confidence interval (Cl) were calculated using random or fixed models. A total of six RCTs including 1100 adult patients with $\mathrm{CHC}$ met the inclusion criteria and the patients were infected with HCV genotype 1-4, with the genotype 1 infection accounting for $73.1 \%$. Meta-analysis showed daclatasvirbased combination therapy yielded a significantly higher probability of achieving the overall RVR (46.43 vs. $18.97 \%$ ) with pooled RR of 3.77 (95\% Cl 1.95-7.28, $p<0.0001$ ) and a slightly higher probability of achieving the overall SVR 24 ( 65.08 vs. $47.77 \%$ ) with pooled RR of 1.41 ( $95 \% \mathrm{Cl} 1.18-1.68, p<0.0001)$, and did not show increased adverse events compared with the pegIFN-a/RBV regimen (control group). Subgroup analysis showed the rate of RVR and SVR ${ }_{24}$ in high-dose daclatasvir (60 mg/day) group were slightly higher than the overall results; the rate of RVR in low-dose daclatasvir (10 mg/day) group was also higher than the control group, but its $\mathrm{SVR}_{24}$ rate was similar between the two groups. Daclatasvir combined with pegIFN-a/RBV is effective and safe in treating adult patients with $\mathrm{CHC}$, especially HCV genotype 1 infection, and daclatasvir (60 mg/day) is a better choice as compared with daclatasvir (10 mg/day).
\end{abstract}

Keywords: Chronic, Daclatasvir, Hepatitis C, Meta-analysis, Randomized controlled trials

\section{Background}

Chronic hepatitis $\mathrm{C}$ virus (HCV) infection is common worldwide, affecting approximately 185 million people globally, and is the cause of 704,000 deaths annually (World Health Organization 2016; Gower et al. 2014; Chen and Ma 2014). About 75-85\% of all patients contracting $\mathrm{HCV}$ will progress to chronic infection, with $15-25 \%$ of patients spontaneously clearing the infection (Centers for Disease Control and Prevention 2014). The progression between various stages of fibrosis can take decades, and often patients are asymptomatic until end-stage disease. Approximately one-third of patients with chronic $\mathrm{HCV}$ infection will develop cirrhosis or

*Correspondence: tangshaohui206@163.com

${ }^{\dagger}$ Qin Peng, Kang Li and Ming Rong Cao contributed equally to this work

1 Department of Gastroenterology, The First Affiliated Hospital, Jinan

University, 613 Huang Pu Avenue, Guangzhou, China

Full list of author information is available at the end of the article hepatocellular carcinoma (World Health Organization 2016). So more and more attentions are paid to the early detection and treatment of chronic hepatitis $\mathrm{C}(\mathrm{CHC})$. The goal of treatment of $\mathrm{CHC}$ is to reduce associated morbidity and mortality and to improve health-related quality of life (AASLD/IDSA/IAS-USA 2014; American Association for the Study of the Liver 2016). Achievement of sustained virological response (SVR) is a surrogate endpoint for these goals (Ghany et al. 2009a, b; European Association for the Study of the Liver 2014a, b). Pegylated interferon- $\alpha$ (pegIFN- $\alpha$ ) in combination with ribavirin (RBV) has always been the current standard of care for $\mathrm{CHC}$, which result in remarkable biochemical and histological improvements in the liver (Chen and Li 2015; European Association for the Study of the Liver 2014a, b). However, patients infected with HCV genotype 1 have experienced a poor response to this therapy 
as observed by SVR rates of only 40-50 \% (Chinese Society of Hepatology et al. 2015).

In recent years, the direct antiviral agents (DAA) have gradually emerged, which include the nonstructural protein $3 / 4 \mathrm{~A}(\mathrm{NS} 3 / 4 \mathrm{~A})$ protease inhibitor, the NS5A inhibitor, the NS5B polymerase inhibitor, the NS4B protease inhibitor, and the NS3 protease inhibitor, etc (Wan et al. 2014). The emergence of these drugs has brought new choice for the treatment. Daclatasvir is a first-in-class, potent, and highly selective NS5A replication complex inhibitor with broad genotypic coverage (genotypes 1-5) and a pharmacokinetic profile supportive of once-daily dosing (Degasperi et al. 2015; Manolakopoulos et al. 2016; Keating 2016). Nettles et al. (2011) conducted the first randomized controlled trial (RCT), showing that daclatasvir in combination with pegIFN- $\alpha /$ RBV achieved satisfactory therapeutic effects. Subsequently, other studies with different design, location, and population further examined the efficacy of daclatasvir in the treatment of $\mathrm{CHC}$. Here, we combined all published RCTs on this issue to quantitatively assess the efficacy and safety of daclatasvir combined with pegIFN- $\alpha$ and ribavirin in the treatment of $\mathrm{CHC}$.

\section{Methods}

\section{Literature search}

A systematic search of PUBMED, EMBASE, COCHRANE, WANFANG, and CNKI (Chinese database) was performed with no year restrictions. The search strategy included the following terms: 'HCV' (e.g. 'hepatitis C', 'hepatitis $\mathrm{C}$ virus', 'HCV infection'); 'daclatasvir' (e.g. 'BMS-790052'); 'RCT' (e.g. 'randomized controlled trial'). We carried out a second retrieval for the references of review.

\section{Inclusion and exclusion criteria}

Trials were considered for inclusion if they met the following four criteria. (a) The research type was RCT design. (b) This study was conducted in patients aged 18-70 years who had chronic HCV infection over 6 months with positive anti-HCV. Additional inclusion criteria included HCV-RNA $\geq 10^{5} \mathrm{IU} / \mathrm{ml}$. Meanwhile, serum urea nitrogen, creatinine and prothrombin activity were at normal levels. (c) Patients in experimental group were treated with daclatasvir in combination with pegIFN/RBV; while patients in control group were treated with placebo in combination with peg-IFN/RBV. (d) The Jadad score of RCTs should not be less than three points.

Trials were excluded if: (a) the study belonged to nonrandomized controlled trial (NRCT) or the Jadad score of RCTs was less than three points; (b) the study didn't provide the outcome or the measurement; (c) the study was literature review or repeated other reports (Fig. 1).

\section{Data extraction}

Data extracted from each study included published information (including the first author and published time); subjects (including the number of patients, gender, age, HCV-RNA content and viral genotype); treatment protocols (including the drugs used in experimental group and control group, dosage regimen, course of the treatment, efficient individual quantity).

\section{Quality assessment}

We conducted a risk of bias assessment based on Jadad scores (Jadad et al. 1996): (a) method of randomization was mentioned; (b) method of randomization was appropriate; (c) the trial was double-blind; (d) method of blinding was identical placebo; (e) there was a description of withdraws and drop outs. If the study complied with any of the above description, it would get one point. The study with total score above 3 was divided into highquality research.

\section{Statistical analysis}

Statistical heterogeneity between studies was examined using the $I^{2}$ value. $I^{2}$ ranges of $25-<50,50-<75$ and $\geq 75 \%$ were considered to represent low, moderate, and high heterogeneity, respectively. If heterogeneity is low, we choose fixed-effects model, and if heterogeneity is moderate or high, we choose random-effects model (Tian et al. 2013). Sensitive analysis was performed to examine the reliability of the results by omitting one study each time and recalculating the pooled RR. Publication bias was evaluated by visual inspection of Begg's funnel plot and tested by the Begg's test (significant at $p<0.1$ ). In addition, the trim-and-fill method was used to adjust the pooled RR and $95 \% \mathrm{CI}$ if observed publication bias existed. All statistical analyses were completed using Stata statistical software version 12.0 .

\section{Results \\ Study characteristics}

A total of 147 potentially relevant studies were identified through the electronic search. Through a review of titles and abstracts, 12 articles were chosen for full review. Six studies retrieved for further review were excluded. The remaining six studies met all criteria and were included in this meta-analysis. Baseline characteristics of included studies were presented in Table 1. Among these papers, there were 926 cases treated with daclatasvir in combination with peg-IFN- $\alpha /$ RBV (daclatasvir group) and 174 cases treated with peg-IFN- $\alpha /$ RBV (control group) and they were infected with $\mathrm{HCV}$ genotype 1-4 infection with the genotype 1 infection accounting for $73.1 \%$, published from 2012 to 2015. The sample sizes of these studies ranged from 42 to 419 . Median age of the patients 

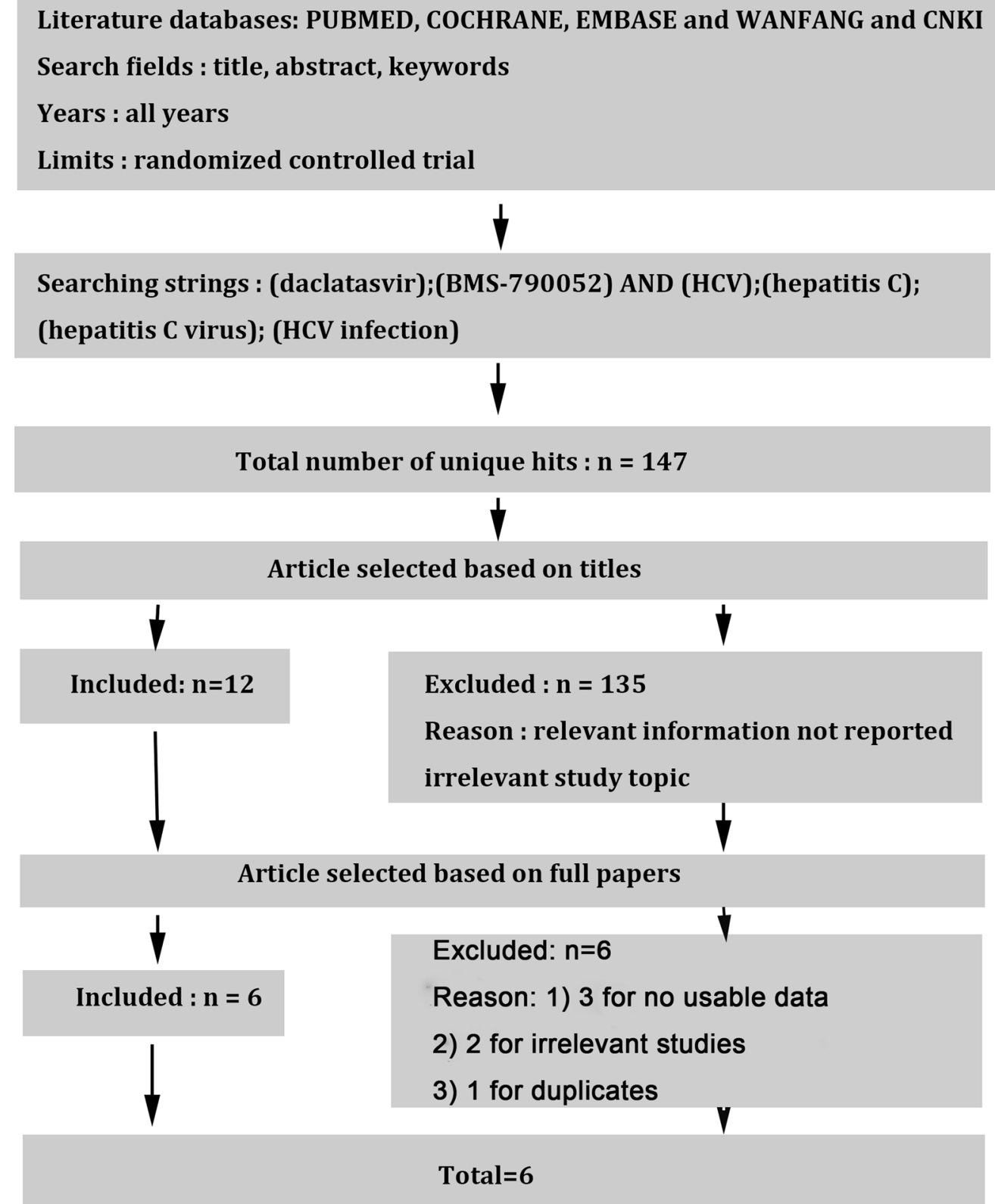

Fig. 1 Search strategy and flow of information relative to the meta-analysis

ranged 50-57 years. The percentage of men in each treatment arm ranged $22.0-75.0 \%$. The quality assessment of all RCTs were greater than or equal to 4 , which indicated that all included articles were high quality (Table 2).

\section{Overall analysis}

\section{Rapid virological response (RVR)}

RVR was defined as an undetectable HCV-RNA level at 4 weeks after treatment initiation. A total of the six studies (Hézode et al. 2015; Dore et al. 2015; Suzuki et al. 2014; Izumi et al. 2014; Pol et al. 2012; Ratziu et al. 2012) were included in this combined analysis. The test for the heterogeneity among the studies showed statistical significance $\left(I^{2}=54.5 \%\right)$, so the random-effects model was used. Meta-analysis results suggested that the overall RVR rate was significantly higher in daclatasvir group (46.43\%) as compared with that in control group $(18.97 \%)(\mathrm{RR}=3.77,95 \%$ CI 1.95-7.28, $p<0.0001$, Fig. 2). Sensitive analysis showed that no individual studies could change the pooled results. Publication 


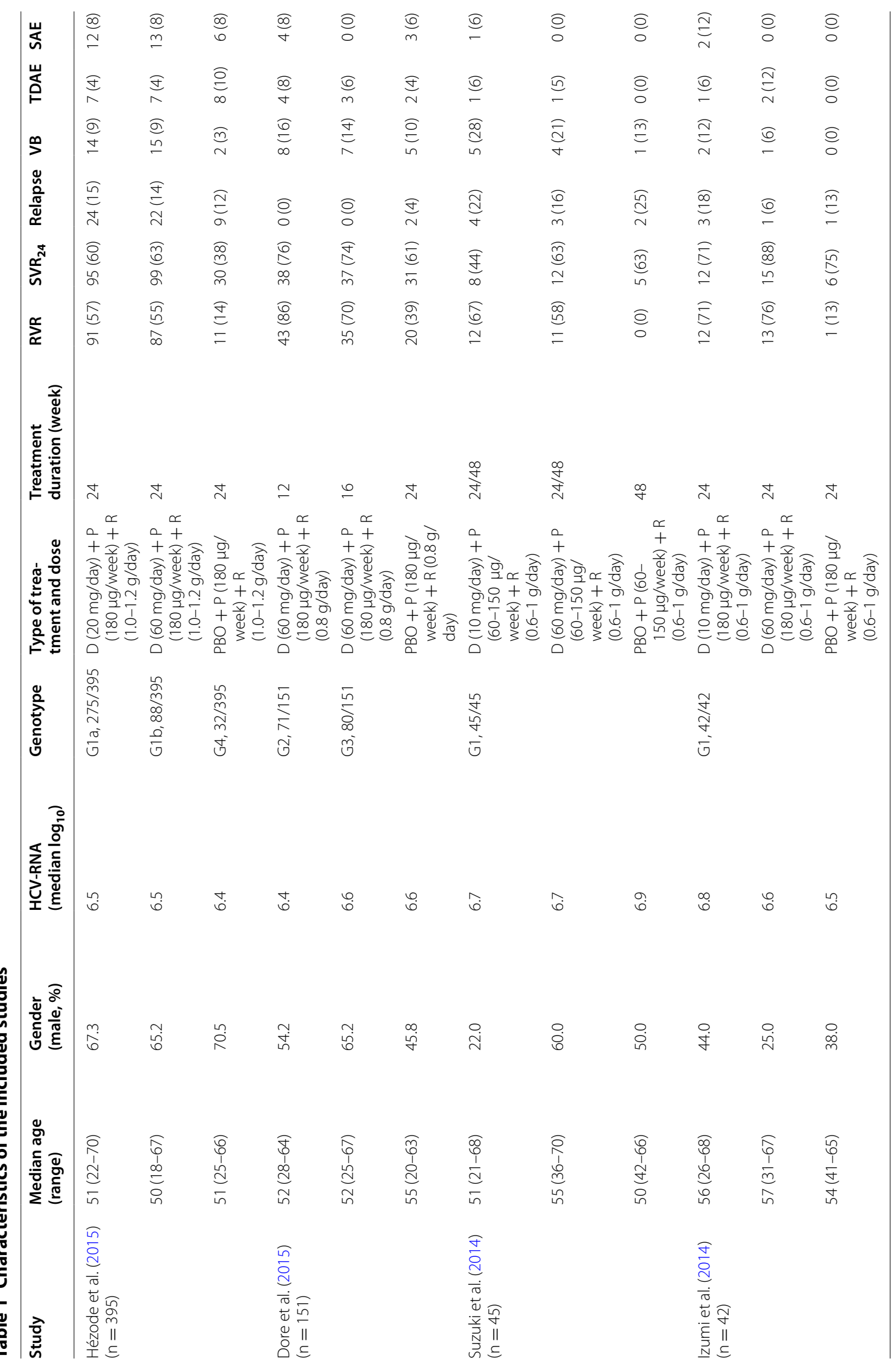




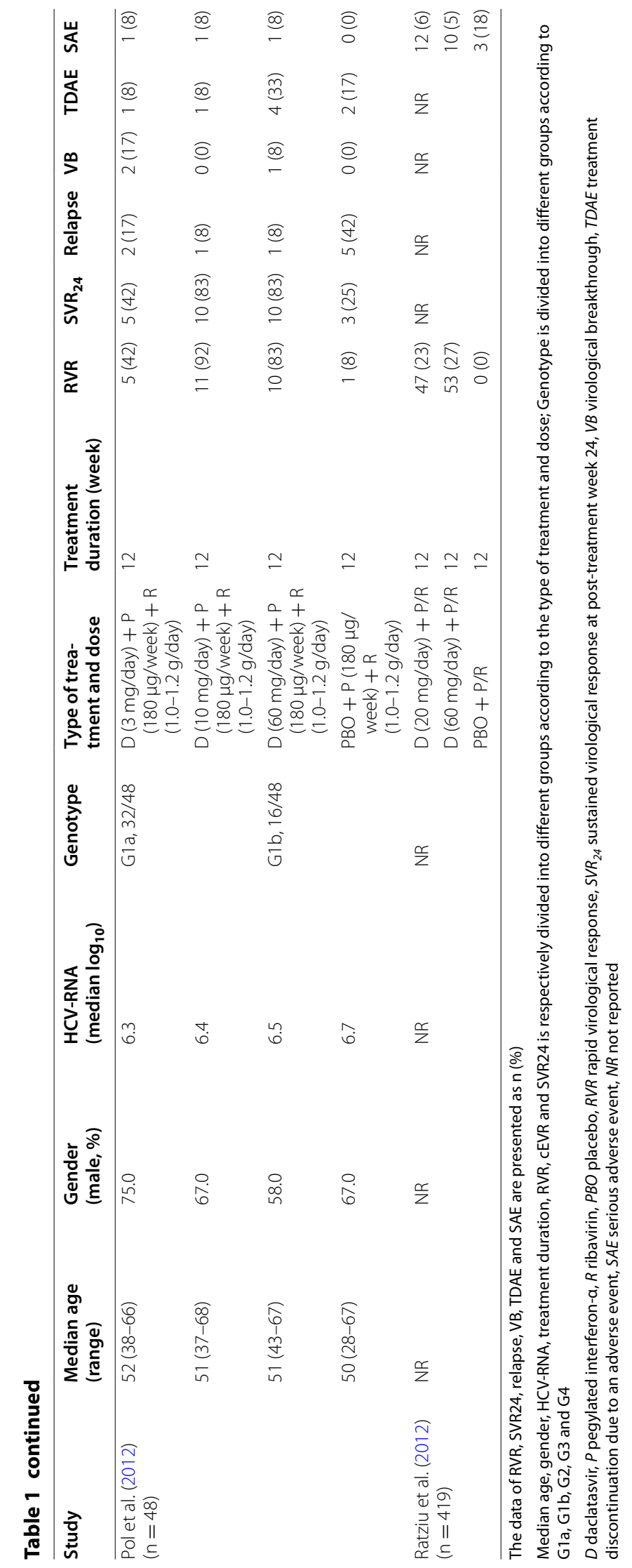


Table 2 Jadad score of clinical trials

\begin{tabular}{|c|c|c|c|c|}
\hline Trial & Randomization & Double-blinding & Withdraw and drop out & Jadad score \\
\hline Hézode et al. (2015) & $\begin{array}{l}\text { Method of randomization was } \\
\text { mentioned and it was appropriate (2) }\end{array}$ & $\begin{array}{l}\text { Method of blinding was } \\
\text { identical placebo (2) }\end{array}$ & $\begin{array}{l}\text { There was a description of } \\
\text { withdraws and drop outs (1) }\end{array}$ & 5 \\
\hline Dore et al. (2015) & $\begin{array}{l}\text { Method of randomization was } \\
\text { mentioned and it was appropriate (2) }\end{array}$ & $\begin{array}{l}\text { Method of blinding was } \\
\text { identical placebo (2) }\end{array}$ & $\begin{array}{l}\text { There was a description of } \\
\text { withdraws and drop outs (1) }\end{array}$ & 5 \\
\hline Suzuki et al. (2014) & $\begin{array}{l}\text { Method of randomization was } \\
\text { mentioned and it was appropriate (2) }\end{array}$ & $\begin{array}{l}\text { Method of blinding was } \\
\text { identical placebo (2) }\end{array}$ & $\begin{array}{l}\text { There was a description of } \\
\text { withdraws and drop outs (1) }\end{array}$ & 5 \\
\hline Izumi et al. (2014) & $\begin{array}{l}\text { Method of randomization was } \\
\text { mentioned and it was appropriate (2) }\end{array}$ & $\begin{array}{l}\text { Method of blinding was } \\
\text { identical placebo (2) }\end{array}$ & $\begin{array}{l}\text { There was a description of } \\
\text { withdraws and drop outs (1) }\end{array}$ & 5 \\
\hline Pol et al. (2012) & $\begin{array}{l}\text { Method of randomization was } \\
\text { mentioned but not described (1) }\end{array}$ & $\begin{array}{l}\text { Method of blinding was } \\
\text { identical placebo (2) }\end{array}$ & $\begin{array}{l}\text { There was a description of } \\
\text { withdraws and drop outs (1) }\end{array}$ & 4 \\
\hline Ratziu et al. (2012) & $\begin{array}{l}\text { Method of randomization was } \\
\text { mentioned but not described (1) }\end{array}$ & $\begin{array}{l}\text { Method of blinding was } \\
\text { identical placebo (2) }\end{array}$ & $\begin{array}{l}\text { There was a description of } \\
\text { withdraws and drop outs (1) }\end{array}$ & 4 \\
\hline
\end{tabular}

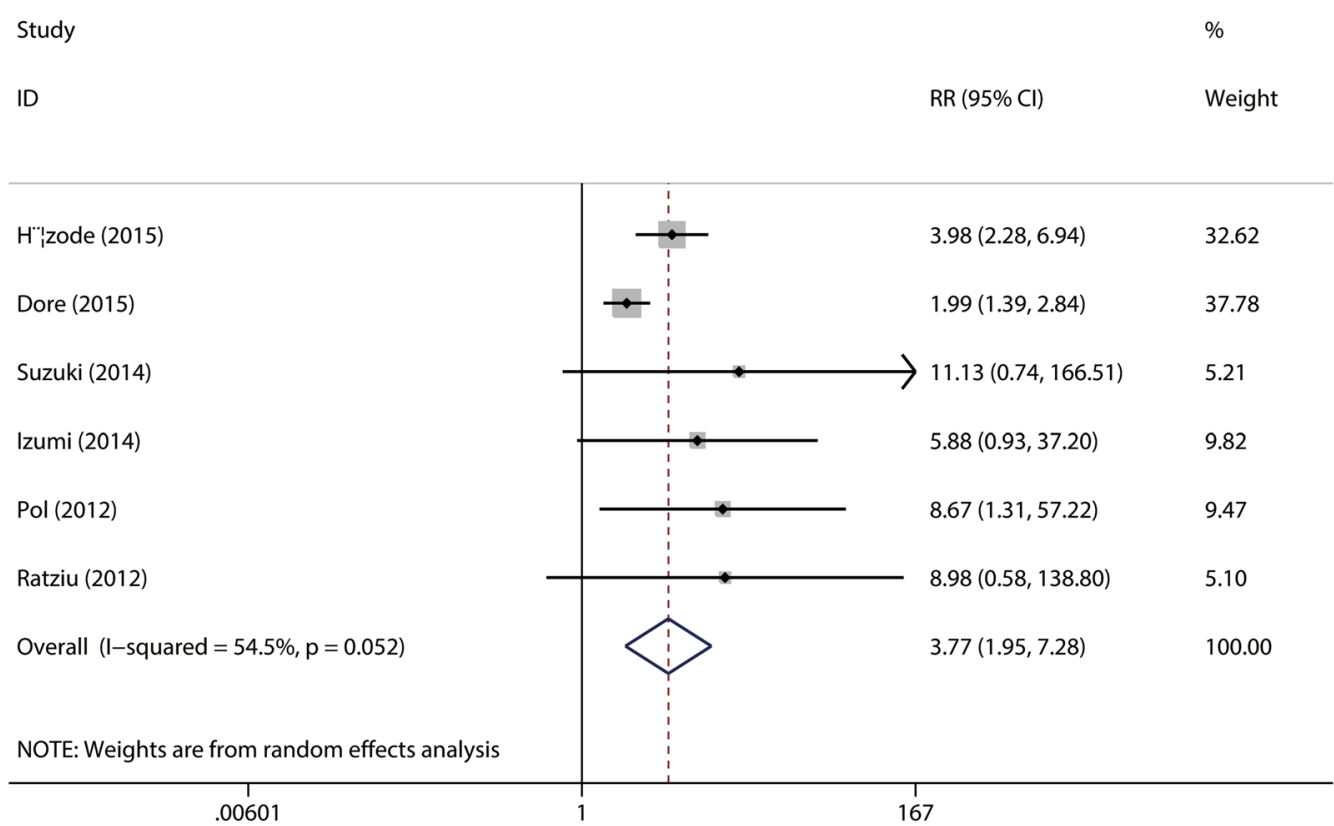

Fig. 2 Forest plot of RVR rate of $D C V+P / R$ and $P B O+P / R$ for $C H C$

bias did not exist $(p=0.851)$ when the Begger test was performed.

\section{Sustained virological response at post-treatment week 24 \\ $\left(S V R_{24}\right)$}

$\mathrm{SVR}_{24}$, defined as an undetectable viral load at the end of treatment and 24 weeks after the end of treatment, historically has been regarded as a virologic cure. A total of the five studies (Hézode et al. 2015; Dore et al. 2015; Suzuki et al. 2014; Izumi et al. 2014; Pol et al. 2012) were included in this combined analysis. The test for the heterogeneity showed that there was no statistical significance
$\left(I^{2}=47.3 \%\right)$, so the fixed-effects model was used. Metaanalysis results revealed that the overall $\mathrm{SVR}_{24}$ rate was significantly higher in daclatasvir group $(65.08 \%)$ as compared with that in control group (47.77\%) $(\mathrm{RR}=1.41$, $95 \%$ CI 1.18-1.68, $p<0.0001$, Fig. 3). Sensitive analysis showed that no individual studies could change the pooled results. Publication bias did not exist $(p=0.624)$ when the Begger test was performed.

Relapse was defined as detectable HCV-RNA during 24 week follow-up after undetectable HCV-RNA at end of treatment. A total of the five studies (Hézode et al. 2015; Dore et al. 2015; Suzuki et al. 2014; Izumi et al. 


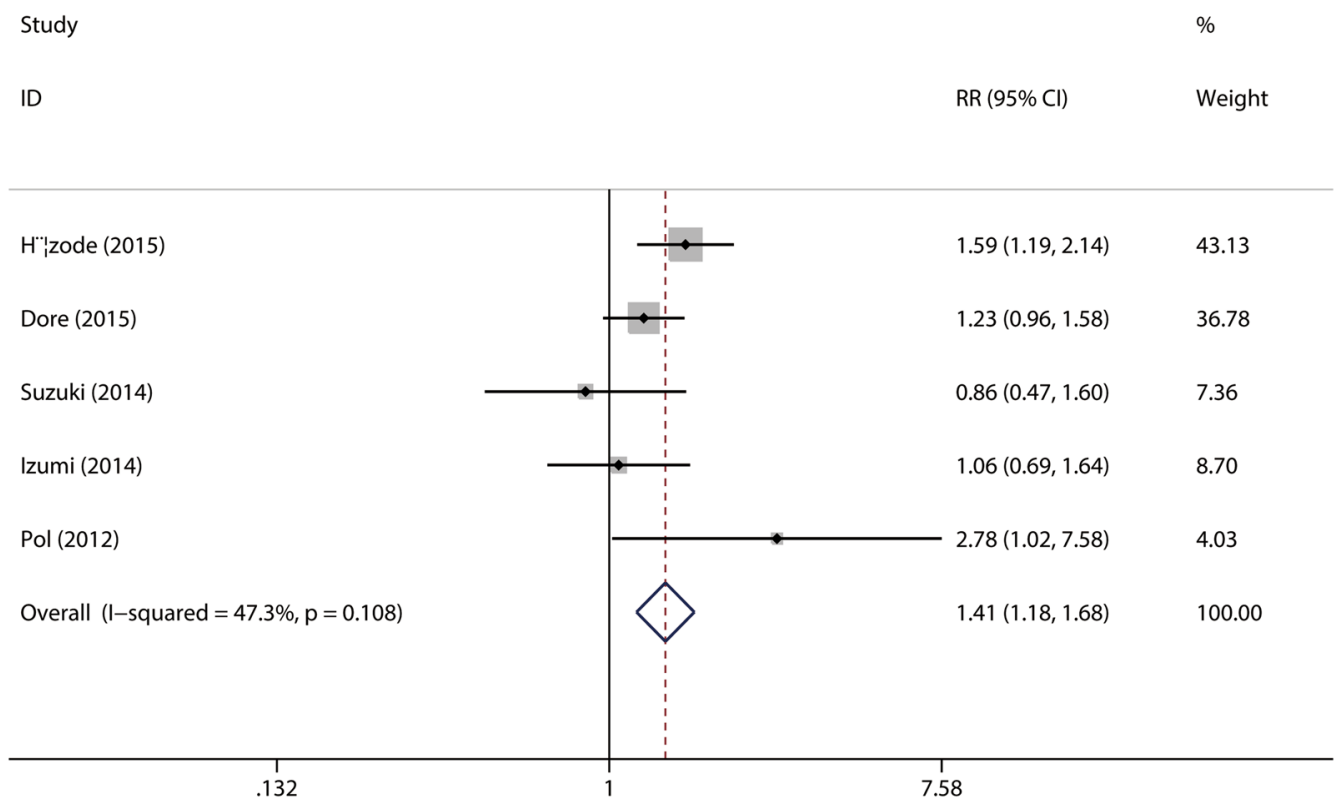

Fig. 3 Forest plot of SVR rate of $D C V+P / R$ and $P B O+P / R$ for $C H C$

2014; Pol et al. 2012) were included in this combined analysis. The test for the heterogeneity showed that there was no statistical significance $\left(I^{2}=43.9 \%\right)$, so the fixedeffects model was used. Meta-analysis results revealed that there were no significant differences between the two groups in the relapse rate $(p=0.40>0.05$, Fig. 4$)$. Sensitive analysis showed that no individual studies could change the pooled results. Publication bias did not exist $(p=0.624)$ when the Begger test was performed.

Treatment discontinuation due to an adverse event (TDAE)

TDAE was defined as subjects who stopped all study drugs due to an adverse event. A total of the five studies (Hézode et al. 2015; Dore et al. 2015; Suzuki et al. 2014;

\section{Study}

ID
$\%$

$\operatorname{RR}(95 \% \mathrm{Cl}) \quad$ Weight

$1.26(0.64,2.46)$

47.91

$0.10(0.01,2.11) \quad 10.95$

$0.76(0.19,2.99)$

10.91

$0.94(0.12,7.32) \quad 5.37$

$0.27(0.09,0.83) \quad 24.87$

$0.81(0.50,1.32) \quad 100.00$

37

Overall (I-squared $=43.9 \%, p=0.129$ )

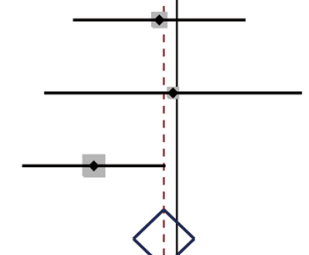

Pol (2012)

plot of relapse rate of $D C V+P$

Fig. 4 Forest plot of relapse rate of $D C V+P / R$ and $P B O+P / R$ for $C H C$ 
Izumi et al. 2014; Pol et al. 2012) were included in this combined analysis. The test for the heterogeneity showed that there was no statistical significance $\left(I^{2}=0 \%\right)$, so the fixed-effects model was used. Meta-analysis results indicated that there were no significant differences between the two groups in the TDAE rate $(p=0.42>0.05$, Fig. 5). Sensitive analysis showed that no individual studies could change the pooled results. Publication bias did not exist $(p=0.624)$ when the Begger test was performed.

\section{Subgroup analysis \\ Effect of high-dose (60 mg/day) use of daclatasvir on CHC}

The $R V R$ rate of daclatasvir ( $60 \mathrm{mg} /$ day) $\quad$ It was defined as the rate of patients who had a HCV viral load below the limit of quantitation or detection at week 4 of treatment with daclatasvir ( $60 \mathrm{mg} /$ day). A total of six studies (Hézode et al. 2015; Dore et al. 2015; Suzuki et al. 2014; Izumi et al. 2014; Pol et al. 2012; Ratziu et al. 2012) were included in the subgroup. The test for the heterogeneity among the studies showed statistical significance $\left(I^{2}=52.2 \%\right)$, so the random-effects model was used. Combined analysis suggested that the RVR rate was significantly higher in daclatasvir (60 mg/day) group (49.90\%) as compared with that in control group (13.97 \%) $(\mathrm{RR}=3.76,95 \% \mathrm{CI}$ 1.97-7.16, $p<0.00001$, Fig. 6). Sensitive analysis showed that no individual studies could change the pooled results. Publication bias did not exist $(p=0.851)$ when the Begger test was performed.
The $S V R_{24}$ rate of daclatasvir ( $60 \mathrm{mg} /$ day) $\quad$ It was defined as the rate of patients who had a negative HCV RNA test 24 weeks after the end of treatment with daclatasvir (60 mg/day). A total of five studies (Hézode et al. 2015; Dore et al. 2015; Suzuki et al. 2014; Izumi et al. 2014; Pol et al. 2012) were included in the subgroup. The test for heterogeneity showed that there was no statistical significance $\left(I^{2}=40.6 \%\right)$, so the fixed-effects model was used. Combined analysis revealed that the $\mathrm{SVR}_{24}$ rate was significantly higher in daclatasvir $(60 \mathrm{mg} /$ day) group $(68.95 \%)$ as compared with that in control group $(47.77 \%)$ $(\mathrm{RR}=1.44,95 \%$ CI 1.21-1.71, $p<0.0001$, Fig. 7). Sensitive analysis showed that no individual studies could change the pooled results. Publication bias did not exist $(p=0.327)$ when the Begger test was performed.

\section{Effect of low-dose (10 mg/day) use of daclatasvir on CHC}

The $R V R$ rate of daclatasvir (10 $\mathrm{mg} /$ day) $\quad$ It was defined as the rate of patients who had a HCV viral load below the limit of quantitation or detection at week 4 of treatment with daclatasvir (10 mg/day). A total of three studies (Suzuki et al. 2014; Izumi et al. 2014; Pol et al. 2012) were included in the subgroup. The test for heterogeneity showed that there was no statistical significance $\left(I^{2}=0 \%\right)$, so the fixed-effects model was used. Combined analysis suggested that the RVR rate was significantly higher in daclatasvir (10 mg/day) group (74.47 \%) as compared with that in control group $(7.14 \%)(\mathrm{RR}=8.79,95 \% \mathrm{CI}$

\begin{tabular}{|c|c|c|}
\hline Study & & $\%$ \\
\hline ID & $\mathrm{RR}(95 \% \mathrm{Cl})$ & Weight \\
\hline H"|zode (2015) & $0.43(0.19,0.99)$ & 63.90 \\
\hline Dore (2015) & $1.78(0.38,8.28)$ & 13.18 \\
\hline Suzuki (2014) & $1.18(0.06,22.58)$ & 4.02 \\
\hline Izumi (2014) & $\rightarrow 1.80(0.10,31.79)$ & 3.96 \\
\hline Pol (2012) & $1.00(0.23,4.31)$ & 14.93 \\
\hline Overall (I-squared $=0.0 \%, p=0.465$ ) & $0.78(0.43,1.42)$ & 100.00 \\
\hline .0315 & 31.8 & \\
\hline
\end{tabular}




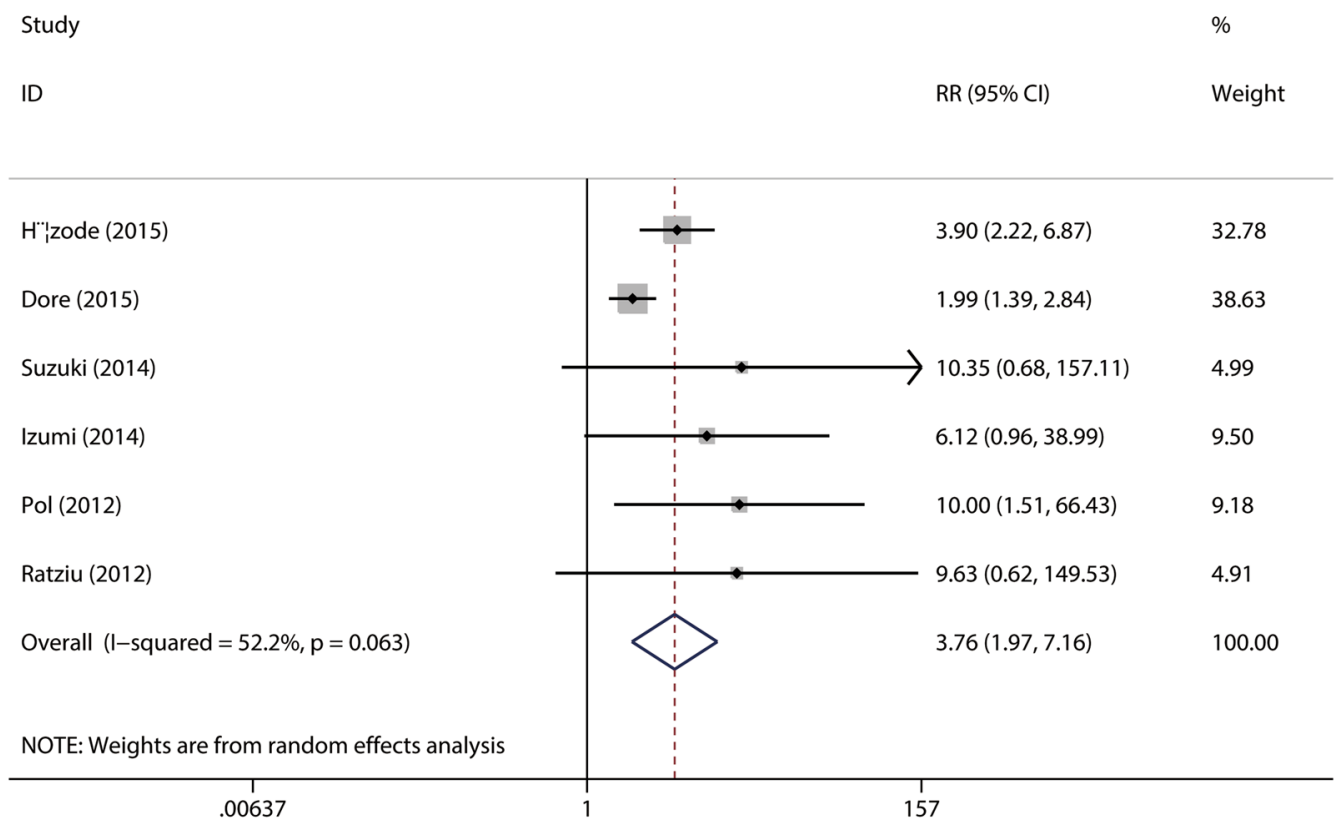

Fig. 6 Forest plot of RVR rate of DCV (60 mg/day) + P/R and PBO + P/R for CHC

\section{Study}

ID

RR $(95 \% \mathrm{Cl}) \quad$ Weight

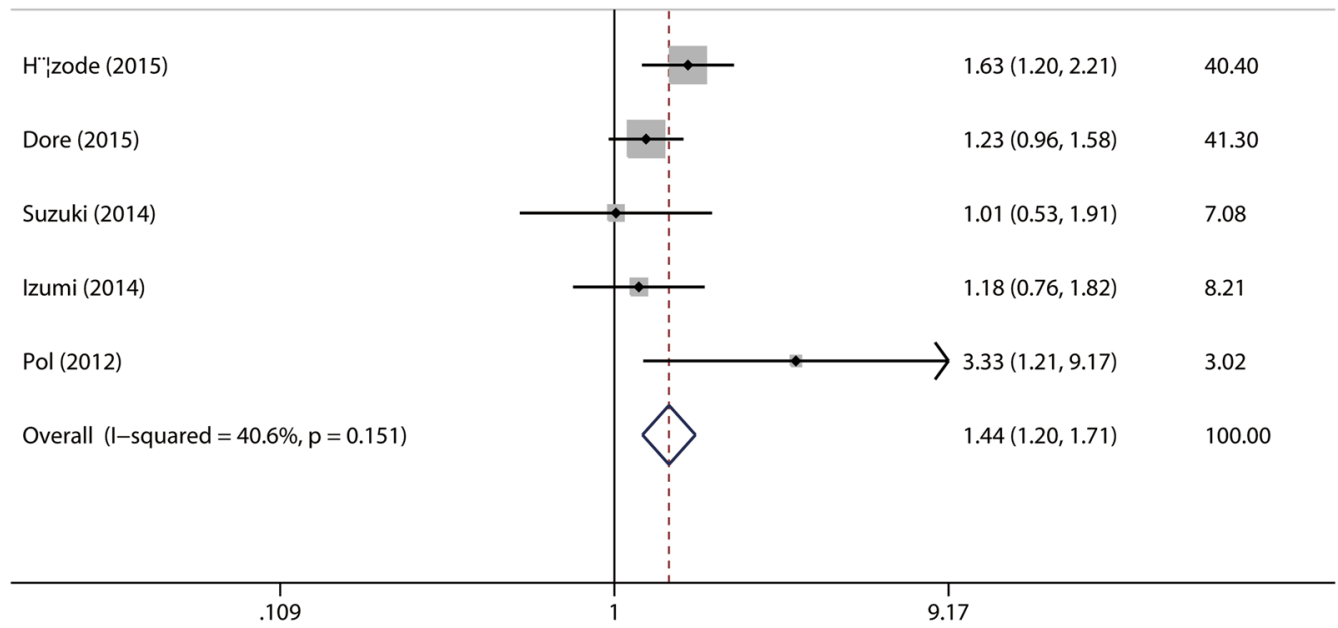

Fig. 7 Forest plot of SVR rate of DCV (60 mg/day) + P/R and PBO + P/R for CHC

2.67-28.95, $p<0.0001$, Fig. 8). Sensitive analysis showed that no individual studies could change the pooled results. Publication bias did not exist $(p=0.602)$ when the Begger test was performed.

The SVR ${ }_{24}$ rate of daclatasvir $(10 \mathrm{mg} /$ day) $\quad$ It was defined as the rate of patients who had a negative HCV RNA test
24 weeks after the end of treatment with daclatasvir $(10 \mathrm{mg} /$ day). A total of three studies (Suzuki et al. 2014; Izumi et al. 2014; Pol et al. 2012) were included in the subgroup. The test for the heterogeneity among the studies showed statistical significance $\left(I^{2}=71.5 \%\right)$, so the random-effects model was used. Combined analysis revealed that there were no significant differences between the two groups in 


\section{Study}

ID
$\%$

$\operatorname{RR}(95 \% \mathrm{Cl})$

Weight

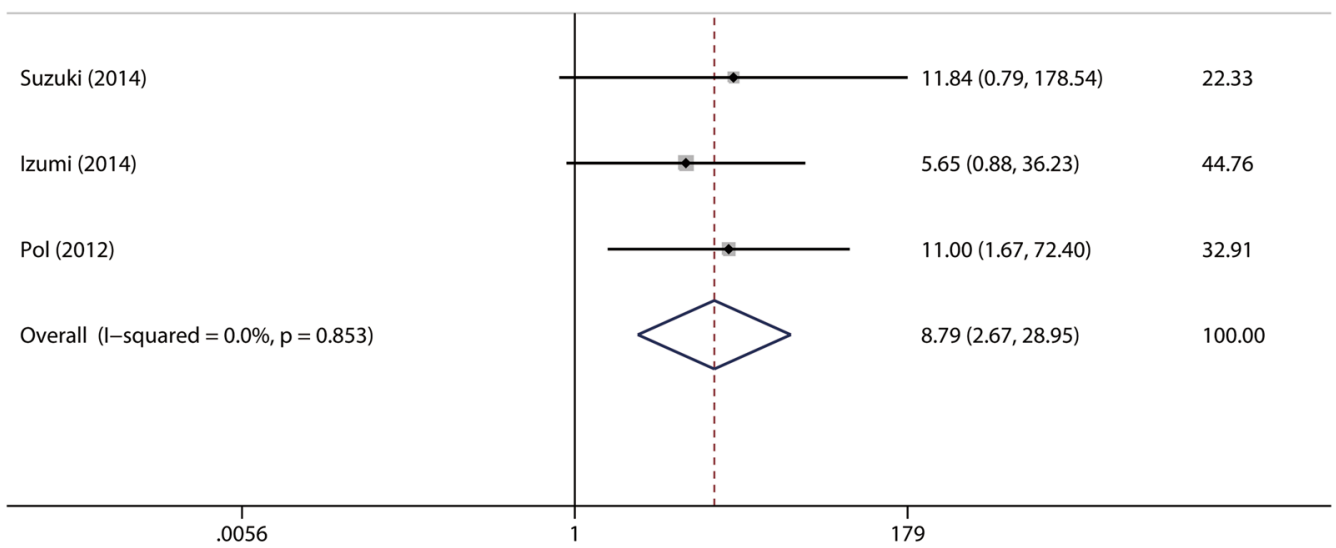

Fig. 8 Forest plot of RVR rate of DCV (10 mg/day) + P/R and PBO + P/R for CHC

the $\mathrm{SVR}_{24}$ rate (63.83 vs. $\left.50.00 \%\right)(p=0.65>0.05$, Fig. 9). Sensitive analysis showed that no individual studies could change the pooled results. Publication bias did not exist $(p=0.602)$ when the Begger test was performed.

\section{Safety analysis}

\section{Nonspecific adverse events}

Four clinical trials (Hézode et al. 2015; Suzuki et al. 2014; Izumi et al. 2014; Pol et al. 2012) mentioned nonspecific adverse events, which were composed of fatigue, headache, insomnia, nausea, diarrhea, decreased appetite, cough, arthralgia, etc. Meta-analysis results indicated that there were no significant differences in the nonspecific adverse events between daclatasvir and control groups ( $p>0.05$, Table 3$)$. Sensitive analysis showed that no individual studies could change the pooled results. Publication bias did not exist $(p>0.05)$ when the Begger test was performed.
Study
$\%$
ID
$\mathrm{RR}(95 \% \mathrm{Cl})$
Weight

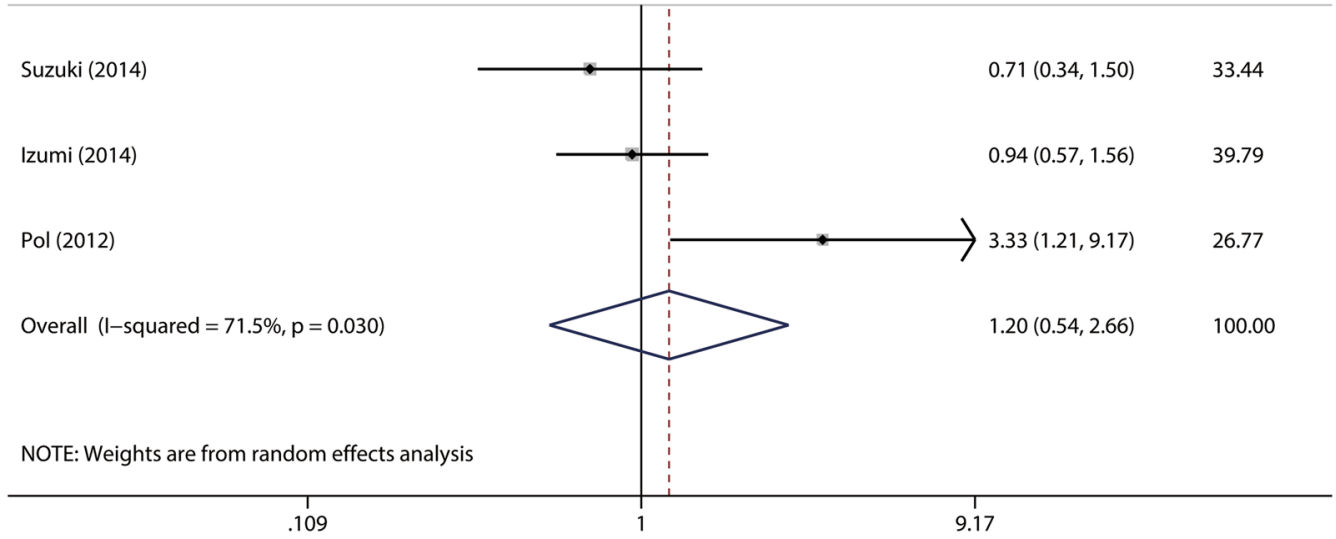

Fig. 9 Forest plot of SVR rate of DCV (10 mg/day) + P/R and PBO + P/R for CHC 
Table 3 Detailed adverse events of the included studies

\begin{tabular}{|c|c|c|c|c|c|}
\hline \multirow[t]{2}{*}{ Category } & \multirow[t]{2}{*}{ Concrete forms } & \multicolumn{2}{|c|}{ Events/total (incidence rate, \%) } & \multirow[t]{2}{*}{$\mathrm{RR}(95 \% \mathrm{Cl})$} & \multirow[t]{2}{*}{$p$ values } \\
\hline & & $D C V+P / R$ & $\mathrm{PBO}+\mathrm{P} / \mathrm{R}$ & & \\
\hline \multirow[t]{8}{*}{ Nonspecific AEs } & Fatigue & $211(49.76)$ & $62(58.49)$ & $0.86(0.72-1.03)$ & 0.11 \\
\hline & Headache & $184(43.40)$ & $48(45.28)$ & $0.96(0.76-1.21)$ & 0.73 \\
\hline & Insomnia & $132(31.13)$ & $36(33.96)$ & $0.86(0.64-1.14)$ & 0.29 \\
\hline & Nausea & $126(32.31)$ & $29(29.59)$ & $0.79(0.37-1.68)$ & 0.53 \\
\hline & Diarrhea & $90(23.20)$ & $54(57.45)$ & $0.52(0.20-1.36)$ & 0.18 \\
\hline & Decreased appetite & $104(24.53)$ & $26(24.53)$ & $0.99(0.69-1.44)$ & 0.98 \\
\hline & Cough & $72(18.60)$ & $53(54.08)$ & $0.66(0.18-2.37)$ & 0.52 \\
\hline & Arthralgia & $66(17.01)$ & $24(25.53)$ & $0.67(0.44-1.01)$ & 0.06 \\
\hline \multirow[t]{2}{*}{ Liver dysfunction } & Elevated ALT & $9(1.84)$ & $1(0.69)$ & $1.51(0.34-6.68)$ & 0.59 \\
\hline & Elevated bilirubin & $4(0.82)$ & $1(0.69)$ & $0.87(0.19-4.07)$ & 0.86 \\
\hline \multirow[t]{3}{*}{ Hematologic abnormalities } & Anemia & $45(8.59)$ & $14(8.92)$ & $0.92(0.53-1.59)$ & 0.77 \\
\hline & Thrombocytopenia & $12(2.46)$ & $6(4.14)$ & $0.63(0.24-1.65)$ & 0.34 \\
\hline & Neutropenia & $139(26.53)$ & $46(29.30)$ & $0.89(0.67-1.19)$ & 0.44 \\
\hline \multirow[t]{3}{*}{ Skin abnormalities } & Rash & $147(28.05)$ & $46(29.30)$ & $0.93(0.71-1.23)$ & 0.63 \\
\hline & Pruritus & $179(34.16)$ & $49(31.21)$ & $1.06(0.81-1.38)$ & 0.67 \\
\hline & Alopecia & $116(27.36)$ & $23(21.70)$ & $1.06(0.50-2.24)$ & 0.88 \\
\hline
\end{tabular}

$A E$ adverse event, $D C V$ daclatasvir, $P$ pegylated interferon- $a, R$ ribavirin, $P B O$ placebo

\section{Liver dysfunction}

Four clinical trials (Hézode et al. 2015; Dore et al. 2015; Suzuki et al. 2014; Izumi et al. 2014) mentioned the effect of daclatasvir on the liver function, which included elevated alanine aminotransferase (ALT), elevated total bilirubin (TBil), etc. Meta-analysis results indicated that there were no significant differences in the liver dysfunction between daclatasvir and control groups $(p>0.05$, Table 3). Sensitive analysis showed that no individual studies could change the pooled results. Publication bias did not exist $(p>0.05)$ when the Begger test was performed.

\section{Hematologic abnormalities}

Five clinical trials (Hézode et al. 2015; Dore et al. 2015; Suzuki et al. 2014; Izumi et al. 2014; Pol et al. 2012) mentioned the effect of daclatasvir on the hematologic system, which included anemia, thrombocytopenia, neutropenia, etc. Meta-analysis results indicated that there were no significant differences in the hematologic abnormalities between daclatasvir and control groups $(p>0.05$, Table 3$)$. Sensitive analysis showed that no individual studies could change the pooled results. Publication bias did not exist $(p>0.05)$ when the Begger test was performed.

\section{Skin abnormalities}

Five clinical trials (Hézode et al. 2015; Dore et al. 2015; Suzuki et al. 2014; Izumi et al. 2014; Pol et al. 2012) mentioned the effect of daclatasvir on the skin, which included rush, pruritus, alopecia, etc. Meta-analysis results indicated that there were no significant differences in the skin abnormalities between daclatasvir and control groups $(p>0.05$, Table 3$)$. Sensitive analysis showed that no individual studies could change the pooled results. Publication bias did not exist $(p>0.05)$ when the Begger test was performed.

\section{Discussion}

Hepatitis $\mathrm{C}$ virus (HCV) is divided to six genotypes and 70 subtypes, of which HCV genotype $1-3$ infection occupy a leading position, and HCV genotype can influence disease characteristics, treatment options, and therapeutic response rates (Chinese Society of Hepatology et al. 2015; Ghany et al. 2009a, b). Due to no immunity and repeated infection, $\mathrm{CHC}$ is a serious viral infectious disease to human health and very difficult to prevent (World Health Organization 2016). Before the direct antiviral agents (DAA) emerged, the treatment of $\mathrm{CHC}$, a regimen of PEG-IFN- $\alpha 2 a$ or $2 b$, and ribavirin (RBV) remains unsatisfactory, particularly in the large number of patients with $\mathrm{HCV}$ genotype 1 infection, whose sustained viral response rates are currently $40 \%$ (Ghany et al. 2009a, b; European Association for the Study of the Liver 2014a, b).

Treatment for HCV infection is rapidly evolving with the introduction of direct-acting antiviral (DAA) agents (Li 2014; Yang and Wang 2014). The Guidelines Development Group recommends that persons with genotype 1 $\mathrm{HCV}$ infection should be considered for treatment with 
the currently approved direct-acting antivirals (telaprevir, boceprevir or simeprevir), given in combination with PEG-IFN and RBV rather than only PEG-IFN and RBV (European Association for the Study of the Liver 2014a, b). However, these drugs have to be taken three times daily and have a high pill burden, and are associated with adverse events, including skin rash and anaemia, which might reduce tolerability and adherence (World Health Organization 2016).

As far as we know, all-oral, interferon-free combinations of drugs are expected to cure more than $90 \%$ of $\mathrm{HCV}$ infections and become a hot issue. Even so, a number of unsolved scientific questions remain. Firstly, IFNbased regimens are generally cheaper than combinations of DAAs without IFN. IFN-based regimens thus could be imposed as first line therapies in some settings (Chen 2016). Secondly, DAAs like sofosbuvir, ledipasvir and grazoprevir have not enter developing countries, such as China. Thirdly, the results of IFN-based therapies depend mainly on the patients' responsiveness to IFN, which is determined genetically, the absence or presence of cirrhosis, and the HCV genotype. However, IFN-free regimens are not yet available or efficacious enough in some subsets of patients (Jean 2014). Fourthly, viral resistance will become an issue for patients who do not respond to all-oral, IFN-free regimens. When the drugs are approved, erroneous prescriptions, treatment of more difficult-to-cure, real-life patients, and/or suboptimal adherence to therapy will generate more frequent treatment failures, owing to selection of viruses that are resistant to the different classes of drugs (Jean 2014). Fifthly, if patients with decompensated cirrhosis or combined with other systemic disease need continuous treatment, DAA combinations will increase the risk of drug-drug interaction (Chen 2016). In summary, at present, patients in developing countries need some acceptable treatment options.

Daclatasvir (DCV), a new oral antiviral drug for $\mathrm{CHC}$, is a HCV NS5A inhibitor. NS5A is a RNA-binding multifunctional viral protein and is essential for viral proliferation by interacting with other HCV nonstructural proteins and cellular proteins (Keating 2016; Scheel and Rice 2013; Qiu et al. 2011). Studies (Fridell et al. 2011; Lee et al. 2011; Wang et al. 2012) have demonstrated that DCV exerts antiviral activity by blocking NS3 protease-mediated cleavage of the viral polyprotein, altering the subcellular localisation of NS5A, preventing NS5A hyperphosphorylation, and inhibiting the formation of viral replication complexes. DCV supports once-daily dosing and covers HCV genotype 1-4 infections.

In the present meta-analysis, we included the six high quality published RCTs with adult CHC patients (Jadad scores $\geq 4$ ) by searching several English and Chinese databases and reviewing relevant articles, showing some evidence for better therapeutic effect of daclatasvir plus the current standard therapeutic regimen (pegIFN- $\alpha$ / $\mathrm{RBV}$ ) on $\mathrm{CHC}$, especially $\mathrm{HCV}$ genotype 1 infection. Daclatasvir-based combination therapy yielded a significantly higher probability of achieving the overall RVR (46.43 vs. $18.97 \%$ ) with pooled RR of 3.77 (95\% CI $1.95-7.28, p<0.0001)$ and a slightly higher probability of achieving the overall $\mathrm{SVR}_{24}(65.08$ vs. $47.77 \%)$ rate with pooled RR of 1.41 (95\% CI 1.18-1.68, $p<0.0001$ ), and did not showed increased adverse events compared with the current standard therapeutic regimen. Further, in the subgroup analysis of high-dose daclatasvir (60 $\mathrm{mg} /$ day) group, the present meta-analysis showed the rate of RVR (49.90\%) with pooled RR of 3.76 (95\% CI 1.97-7.16, $p<0.0001)$ and the rate of $\operatorname{SVR}_{24}(68.95 \%)$ with pooled RR of 1.44 (95\% CI 1.21-1.71, $p<0.0001$ ) were slightly higher than those in the overall analysis. In the subgroup analysis of low-dose daclatasvir $(10 \mathrm{mg} /$ day) group, although daclatasvir-based combination regimen also indicated a significantly higher probability of achieving the RVR (74.47 vs. $7.14 \%$ ) with pooled RR of 8.79 (95\% CI 2.67-28.95, $p<0.0001$ ), the $\mathrm{SVR}_{24}$ rate was similar between the daclatasvir and control groups (63.83 vs. $50.00 \%)(p=0.65)$. However, the subgroup analysis of low-dose daclatasvir $(10 \mathrm{mg} /$ day) group only included the three studies, and obviously the reliability of the results was poorer than high-dose daclatasvir $(60 \mathrm{mg} /$ day) group (including the six studies). The above results suggest that daclatasvir is a powerful and direct antiviral agents with improved RVR and SVR rates, oral route of delivery, once-daily administration, and less side effects. Therefore, it is recommended that daclatasvir, pegIFN and RBV triple therapy could be used as a treatment of $\mathrm{CHC}$, especially HCV genotype 1 infection. As far as we know, this was the first meta-analysis that revealed that daclatasvir in combination with peg-IFN- $\alpha /$ RBV could achieve satisfactory therapeutic effects.

There were limitations to our meta-analysis that should be considered. The main limitation of this study was a small number of included RCTs and patients (six RCTs and 1100 patients). Secondly, the course of treatment were not consistent among the six RCTs with large span (12-48 weeks). Thirdly, daclatasvir emerged late, and the observation time of the included RCTs was 24 weeks with a lack of longer follow-up information, so the long-term efficacy was unclear. Fourthly, HCV genotype 1 infection accounted for $73.1 \%$, genotype $2-3$ infection $22.2 \%$, and genotype 4 infection $4.7 \%$ in the included 1100 adult patients. Due to the limited number of cases, we couldn't provide subgroup analysis data on the basis of the four genotypes. Lastly, the limitation of possible publication bias should be taken into consideration because the study 
with positive results were easier to be reported, although possibility of publication bias did not existed using the Begger test.

In summary, this meta-analysis indicated that highdose daclatasvir $(60 \mathrm{mg} /$ day $)$ in combination with pegIFN- $\alpha / \mathrm{RBV}$ is effective and safe in treating adult patients with $\mathrm{CHC}$, especially $\mathrm{HCV}$ genotype 1 infection. We believe daclatasvir in combination with peg-IFN- $\alpha / \mathrm{RBV}$ could be respected as a natural bridge between the past (peg-IFN and ribavirin) and the current (IFN free direct antiviral agents), which has guiding significance to clinical work. To obtain an exact finding with respect to daclatasvir use of $\mathrm{CHC}$ treatment, additional high-quality, large sample and multicenter, randomized, doubleblind, placebo-controlled clinical trials on this issue are needed.

\section{Abbreviations}

CHC: chronic hepatitis C; HCV: chronic hepatitis $\mathrm{C}$ virus; $\mathrm{RCT}$ : randomized controlled trial; DAA: direct antiviral agent; NS3/4A: nonstructural protein 3/4A; DCV: daclatasvir; pegIFN-a: peginterferon-a; RBV: ribavirin; placebo: PBO; RVR: rapid virological response; $S_{V} R_{24}$ : sustained virological response at post-treatment week 24; VB: virological breakthrough;TDAE: treatment discontinuation due to an adverse event; SAE: serious adverse event; ALT: alanine aminotransferase; TBil: total bilirubin; RR: risk ratio; Cl: confidence interval.

\section{Authors' contributions}

PQ Collected the data and wrote the manuscript. LK and CMR collected the data and confirmed statistical analysis. BCQ and THJ designed the study and wrote the manuscript. TSH Directed the study and collected the data. All authors read and approved the final manuscript.

\section{Author details \\ ${ }^{1}$ Department of Gastroenterology, The First Affiliated Hospital, Jinan Univer- sity, 613 Huang Pu Avenue, Guangzhou, China. ${ }^{2}$ Department of Gastroenterol- ogy, The Affiliated HeXian Memorial Hospital, Southern Medical University, Guangzhou, China. ${ }^{3}$ Department of General Surgery, The First Affiliated Hospital, Jinan University, Guangzhou, Guangdong, China. ${ }^{4}$ Department of Gastroenterology, The Affiliated Shenzhen Shajing Hospital, Guangzhou Medical University, Shenzhen 518104, China.}

\section{Acknowledgements}

None.

\section{Competing interests}

The authors declare that they have no competing interests.

\section{Informed consent}

This study was approved by the Ethics Committee of the First Affiliated Hospital of Jinan University. As this study was performed on public articles, informed consents was obtained from all individual participants by each included studies.

Received: 6 June 2016 Accepted: 5 September 2016 Published online: 15 September 2016

\section{References}

AASLD/IDSA/IAS-USA (2014) Recommendations for testing, managing, and treating hepatitis C. http://www.hcvguidelines.org. Accessed 11 Aug 2014
American Association for the Study of the Liver (2016) Recommendations for testing, managing, and treating hepatitis C. http://www.hcvguidelines. org/fullreport. Accessed 11 Aug 2016

Centers for Disease Control and Prevention (2014) Hepatitis C FAQs for healthcare professionals. http://www.cdc.gov/hepatitis/HCV/HCVfaq. htm\#section1. Accessed 1 Aug 2014

Chen GF (2016) The problems and challenges of the treatment of chronic hepatitis C in DAAs era. J Med Res 45:1-7

Chen GF, Li B (2015) The progress and prospect of treatment of the hepatitis C virus infection. J Med Res 44:1-17

Chen PY, Ma AX (2014) Meta-analysis of the effectiveness on peginterferon for chronic hepatitis C. Evid Based Med 31:345-355

Chinese Society of Hepatology, Society of Infectious Diseases of Chinese Medical Association (2015) Guidelines for the prevention and treatment of hepatitis C. Chin J Hepatol 3:19-35

Degasperi E, Aghemo A, Colombo M (2015) Daclatasvir for the treatment of chronic hepatitis C. Expert Opin Pharmacother 16:2679-2688

Dore GJ, Lawitz E, Hézode C et al (2015) Daclatasvir plus peginterferon and ribavirin is noninferior to peginterferon and ribavirin alone, and reduces the duration of treatment for HCV genotype 2 or 3 infection. Gastroenterology 148:355-366

European Association for the Study of the Liver (2014a) EASL clinical practice guidelines: management of hepatitis $C$ virus infection. J Hepatol 60:392-420

European Association for the Study of the Liver (2014b) EASL recommendations on treatment of hepatitis C 2014. J Hepatol 61:373-395

Fridell RA, Qiu D, Valera L et al (2011) Distinct functions of NS5A in hepatitis C virus RNA replication uncovered by studies with the NS5A inhibitor BMS790052. J Virol 85:7312-7320

Ghany MG, Strader DB, Thomas DL et al (2009a) Diagnosis, management, and treatment of hepatitis C: an update. Hepatology 49:1335-1374

Ghany MG, Strader DB, Thomas DL, American Association for the Study of Liver Diseases et al (2009b) Diagnosis, management, and treatment of hepatitis C: an update. Hepatology 49:1335-1374

Gower E, Estes C, Blach S et al (2014) Global epidemiology and genotype distribution of the hepatitis $C$ virus infection. J Hepatol 61:45-57

Hézode C, Hirschfield GM, Ghesquiere W et al (2015) Daclatasvir plus peginterferon alfa and ribavirin for treatment-naive chronic hepatitis $\mathrm{C}$ genotype 1 or 4 infection: a randomised study. Hepatology 64:948-956

Izumi N, Yokosuka O, Kawada N et al (2014) Daclatasivir combined with peginterferon alfa- $2 \mathrm{~b}$ and ribavirin in Japanese patient infected with hepatitis $C$ genotype 1. Antivir Ther 19:501-510

Jadad AR, Moore RA, Carroll D et al (1996) Assessing the quality of reports of randomized clinical trails: is blinding necessary? Control Clin Trials 17:1-121

Jean MP (2014) New hepatitis C therapies: the toolbox, strategies, and challenges. Gastroenterology 146:1176-1192

Keating GM (2016) Daclatasvir: a review in chronic hepatitis C. Drugs 76:1381-1391

Lee C, Ma H, Hang JQ et al (2011) The hepatitis C virus NS5A inhibitor (BMS790052) alters the subcellular localization of the NS5A non-structural viral protein. Virology 414:10-18

Li GY (2014) Efficiency of different peginterferons and ribaviron for the treatment of CHC. Anti Infect Pharm 11:528-530

Manolakopoulos S, Zacharakis G, Zissis M et al (2016) Safety and efficacy of daclatasvir in the management of patients with chronic hepatitis C. Ann Gastroenterol 29:282-296

Nettles RE, Gao M, Bifano M et al (2011) Multiple ascending dose study of BMS790052, an NS5A replication complex inhibitor, in patients infected with hepatitis C virus genotype 1. Hepatology 54:1956-1965

Pol S, Ghali RH, Rustgi VK et al (2012) Daclatasvir for previously untreated chronic hepatitis C genotype-1 infection: a randomised, parallel-group, double-blind, placebo-controlled, dose-finding, phase 2a trial. Lancet Infect Dis 12:671-677

Qiu D, Lemm JA, O'Boyle DR II et al (2011) The effects of NS5A inhibitors on NS5A phosphorylation, polyprotein processing and localization. J Gen Virol 92:2502-2511

Ratziu V, Gadano A, Pol S et al (2012) Triple therapy with Daclatasvir (DCV; BMS-790052), peginterferon alfa/2a and ribavirin in HCV-infected prior null and partial responders: 12 week results of phase $2 \mathrm{~B}$ command- 2 trial. J Hepatol 56:478-479 
Scheel TK, Rice CM (2013) Understanding the hepatitis C virus life cycle paves the way for highly effective therapies. Nat Med 19:837-849

Suzuki F, Toyota J, Ikeda K et al (2014) A randomized trial of daclatasivir with peginterferon alfa-2b and ribavirin for HCV genotype 1 infection. Antivir Ther 19:491-499

The World Health Organization (2014) Guidelines for the screening, care and treatment of persons with hepatitis $\mathrm{C}$ infection. Global Hepatitis Programme, pp 1-122

Tian JH, Li L, Zhao Y et al (2013) Writing and reporting of network meta-analysis. Chin J Drug Eval 30(321-323):333
Wan JL, He X, Bai M (2014) Research progress on combination therapeutic regimen of direct anti HCV agents. Drug Clin 29:442-446

Wang C, Jia L, Huang H et al (2012) In vitro activity of BMS-790052 on hepatitis C virus genotype 4 NS5A. Antimicrob Agents Chemother 56:1588-1590 World Health Organization (2016) Guidelines for the screening, care and treatment of persons with hepatitis $C$ infection: updated version. GUIDELINES $1-138$

Yang XY, Wang JX (2014) Advance in research of anti-HCV drugs and therapies. Chin J New Drugs 23:2624-2630

\section{Submit your manuscript to a SpringerOpen ${ }^{\circ}$ journal and benefit from:}

- Convenient online submission

\section{- Rigorous peer review}

- Immediate publication on acceptance

- Open access: articles freely available online

- High visibility within the field

- Retaining the copyright to your article 